\title{
Saberes e sabores do turismo na Paraíba: uma análise de um Guia de Viagem
}

Knowledges and flavours in Paraíba: an analysis a Travel Guide

Saberes y sabores en Paraíba: un análisis de una Guía de Viaje

Marina Prado Santiago

Associação Nordestina de Albergues (ANA), Brasil

marina@slowhostel.net

DOI: https://doi.org/10.18472/cvt.19n3.2019.1460

Redalyc: http://www.redalyc.org/articulo.oa?

id $=115461709002$

\author{
Julio César Cabrera Medina \\ Universidade Estadual da Paraiba (UEPB), Brasil \\ juliocabreramedina@gmail.com \\ Maria Dilma Simóes Brasileiro \\ Universidade Federal da Paraíba (UFPB), Brasil \\ dsbrasileiro@gmail.com
}

Recepción: 24 Abril 2018

Aprobación: 02 Agosto 2019

\section{Resumo:}

As resenhas gastronômicas dos guias de viagens constroem uma imagem não somente da oferta de restaurantes do destino, mas também da cultura, dos hábitos alimentares e das tradições dos sabores dos lugares. Neste sentido, este estudo tem como objetivo compreender como a gastronomia paraibana se apresenta como atrativo turístico no Guia Quatro Rodas. Mais especificamente, analisa como a gastronomia de João Pessoa, capital da Paraíba (Brasil), é apresentada por este guia para a demanda turística. Este estudo é de abordagem qualitativa e os resultados demonstram que o Guia reforça a ideia de um nordeste reduzido ao sertão, ao apresentar hábitos alimentares que remetem à identidade alegórica da figura do povo sertanejo, mesmo em territórios litorâneos. As mensagens veiculadas desvalorizam a diversidade de sabores e de transformações da própria cozinha nordestino-paraibana, assim como a oferta de novas opções gastronômicas na capital paraibana.

Palavras-ChaVe: Guia Turístico, Gastronomia, Identidade.

\section{Abstract:}

The gastronomic reviews of the travel guides built an image not only of the offer of restaurants available in a destination, but also of the culture, the eating habits and the local flavors traditions. In this regard, this study aims to understand how gastronomy of Paraíba (Brasil) is presented as a tourist attraction in Guia 4 Rodas. More specifically, it analyses how João Pessoa's gastronomy, capital of Paraíba state, is presented by this travel book guide for a tourist demand. This study has a qualitative approach and results show how the guide reinforces the idea of a Brazilian northeast reduced to sertão, presenting eating habits, on the coastline, that referring to an allegorical figure of sertanejo. The message published depreciates the diversity of flavours and all the transitions of Brazilian northeast-Paraíba cuisine, as well as the offer of new gastronomic options in the capital of Paraíba

KEYWORDS: Tourist Guide, Gastronomy, Identity.

\section{Resumen:}

Las descripciones gastronómicas recogidas en las guías de viajes construyen una imagen no sólo de la oferta de restaurantes en el destino, sino también de la cultura, de los hábitos alimenticios y de los sabores tradicionales del lugar. En este sentido, este estudio tiene como objetivo comprender como la gastronomía de Paraíba (Brasil) es ofrecida como atractivo turístico en la 'Guía Cuatro Ruedas'. Concretamente, analiza como la gastronomía de João Pessoa, capital del Estado de Paraíba, es representada en esta guía para la demanda turística. La metodología utilizada es cualitativa y los resultados demuestran que la guía refuerza la idea de un nordeste reducido a la región del interior al presentar hábitos alimenticios que remiten a la identidad alegórica de la figura del pueblo del interior, aunque se trata de un territorio del litoral. Las imágenes proyectadas en la guía desvalorizan la diversidad de

\section{Notas DE AUTOR}

(in memoriam) 
sabores y las transformaciones de la propia cocina de la región, así como la oferta de nuevas opciones gastronómicas en la capital de Paraíba.

Palabras clave: Guía Turística, Gastronomía, Identidad.

\section{INTRODUÇÃO}

A identidade de um povo é construída a partir dos costumes do cotidiano. O alimentar-se, por exemplo, não significa apenas o saciar a fome, mas transmite saberes e fazeres de tradições que são construídos social e culturalmente, isto porque a escolha de determinados alimentos, em detrimento de outros, reflete a complexidade dos processos econômicos e socioculturais dos territórios, que condicionam, nos diversos contextos, o que se come e como se come.

$\mathrm{O}$ ato de comer não é um ato isolado e de caráter exclusivamente pessoal, pois carrega, em si, um forte elo entre algo que é universal, a fome, e algo que é particular, a escolha do quê, onde e como comer (SILVA, 2005). Reconhece-se, portanto, que no momento da alimentação, padróes coletivamente construídos, aceitos e compartilhados por determinados indivíduos e comunidades são vivenciados, criando, ao mesmo tempo, identidade e diferenciação entre os grupos socioculturais.

Os alimentos e os saberes culinários são, portanto, ferramentas de afirmação e transmissão de identidade que expressam a cultura de um território, podendo ser alçadas ao status de atrativo cultural e produto turístico. Autores como Lévi-Strauss (1978), Bourdieu (1988) e Da Matta (1991) elucidam, em seus estudos, a inerente relação havida entre a comida e a identidade sociocultural.

Lévi-Strauss (1978) desvela como a cozinha é uma referência cultural nas escolhas do alimento, responsável também por disseminar valores e tabus, de geração em geração. Ainda segundo esse autor, o consumo dos alimentos crus e cozidos na nossa sociedade faz a distinção entre um estado de selvageria, que corresponde ao alimento cru e o universo socialmente elaborado e aceitável, que corresponde ao alimento cozido. Da Matta (1991) ressalta a relação simbólica entre a comida e a construção identitária de um povo, ao retomar os estudos de Lévi-Strauss. O universo da comida e dos sabores integra, portanto, os elementos de construção das peculiaridades próprias de cada território.

A associação entre o universo da comida e o turismo, quando bem construídas, podem ser o principal atrativo turístico de um destino, como defendem Botelho (2006) e Barroco (2008). Para esses autores, o potencial que a gastronomia possui em atrair pessoas para o destino, torna-se o diferencial, o elemento que interliga a memória sensorial (sabores, aromas, cores e texturas) e a memória espacial (lugar, espaço). Essas memórias relacionam-se a outros atrativos do destino, criando um laço mais estreito entre o turista (que imerge na cultura do outro, do local) e o autóctone (que acolhe o olhar do outro, do turista). Neste contexto, o turista é estimulado a se aproximar da cultura do lugar e a vivenciá-la como experiência turística. Por meio da gastronomia, o turista tem a possibilidade de entender e compartilhar novos traços e expressões culturais e naturais (clima, solo, vegetação) do destino (CUNHA; OLIVEIRA, 2009), estabelecendo, portanto, um vínculo simbólico com o lugar.

Como valor simbólico, a associação da gastronomia típica, com a história de um povo e seu contexto cultural, faz de cada prato um símbolo do lugar, que reafirma e consolida a imagem desse povo. Neste sentido, o valor e o significado da imagem construída à gastronomia do lugar são atribuídos, primeiramente, ao reconhecimento dos próprios indivíduos do lugar para que, posteriormente, sejam reconhecidos pelas pessoas de fora, ou seja, pelos turistas.

A Gastronomia Típica, como afirma Fagliari (2005), cumpre o papel de integrante cultural entre dois povos, sendo exímio produto a ser trabalhado pelo turismo. Ao transformar a gastronomia típica em atrativo turístico, autóctones e turistas se beneficiam, pois um tem a certeza da revitalização e preservação de suas receitas e rituais culinários e, o outro (turista), tem a possibilidade de vivenciar e trocar experiências culturais. Estas trocas retratam, assim, o "eu" (autóctone) a sua cotidiana expressão identitária. 
Um elemento que tem contribuído para a divulgação da Gastronomia Típica são os guias de viagem. Esses guias selecionam o que os turistas podem conhecer em cada viagem, direcionando o olhar do turista para o que pode ser saboreado. Essas indicações favorecem alguns patrimônios culturais em detrimento de outros, atribuindo um maior valor econômico aos produtos e lugares selecionados e divulgados, uma vez que aumenta a demanda nos destinos. Além de orientar e influenciar diretamente as preferências e opinióes dos turistas, os guias turísticos influenciam a construção do imaginário da realidade do destino a ser visitado.

O que antes era consumido como uma necessidade primária de saciar a fome, a partir do turismo, tornase um produto com forte apelo mercadológico, como por exemplo, o bolo de rolo, o acarajé, a cachaça e a rapadura do nordeste brasileiro. Este apelo turístico altera o significado primário do alimento - nutrir-se -, para um símbolo imaterial importante, a ponto de ser considerado um presente que será comprado pelos turistas. Neste sentido, este estudo busca compreender como a gastronomia paraibana se apresenta como atrativo turístico. Mais especificamente, analisa como a gastronomia de João Pessoa, capital da Paraíba, é apresentada pelo Guia Quatro Rodas para a demanda turística.

\section{PROCEDIMENTOS METODOLÓGICOS}

Este estudo é de abordagem qualitativa. Os estudos qualitativos se baseiam na interpretação dos fenômenos e na atribuição de significados, ou seja, "o processo e seu significado são os focos principais" desta abordagem (SILVA; MENEZES, 2001, p. 20). Conforme também analisam Denzin e Lincoln (2000), os pesquisadores qualitativos buscam não somente compreender e interpretar os dados, mas também os significados que são atribuídos a esses dados. Para Brasileiro (2005, p. 164), o método qualitativo "parte do pressuposto de que o mundo social é um mundo construído com símbolos e significados”, que deve ser analisado utilizando um processo compreensivo da realidade.

O recorte temporal utilizado para este estudo foi o período das ediçóes de 2005 a 2015 do Guia Brasil Quatro Rodas. Optou-se por analisar este período em decorrência do lançamento do Programa Nacional de Regionalização do Turismo (BRASIL, 2004). O Programa Nacional de Regionalização do Turismo do Governo Federal tem uma perspectiva regional e busca, por meio de suas diretrizes, fomentar o desenvolvimento territorial, além de atribuir valores econômicos, sociais e culturais aos territórios por meio do turismo. Assim mesmo, este programa reconhece e enaltece as múltiplas identidades e formas de expressões presentes no território brasileiro.

Os dados foram analisados por meio da Análise de Conteúdo (BARDIN, 2009). A primeira fase consistiu na leitura flutuante das edições do Guia Brasil Quatro Rodas do período de 2005 a 2015. Esse procedimento buscou compreender o sentido dos textos dos guias, tendo como objetivo elucidar, tanto as mensagens explícitas, como as implícitas, que estão por trás da superfície textual. Foram definidas três categorias analíticas no estudo: os restaurantes citados no guia no contexto da cidade; o ambiente sociocultural dos restaurantes analisados e o sentido da gastronomia regional dos restaurantes regionais analisados. Neste sentido, foi utilizado o procedimento de "caixas" (BARDIN, 2009), nas quais foram colocadas as narrativas dos textos dos guias analisados dentro das três categorias anteriormente citadas.

A segunda fase da Análise de Conteúdo teve, como objetivo, realizar as inferências a partir dos recortes dos textos dos guias quanto às categorias analisadas. A inferência confere relevância teórica a esse procedimento, já que implica análises e interpretações dos textos à luz de teorias sobre o tema. $\mathrm{O}$ entendimento dos significados dos conteúdos dos textos dos guias, explícitos e implícitos, possibilitou interpretar os sentidos das narrativas dos guias. Buscou-se entender as relações e as contradições nos textos dos guias inferindo, de maneira lógica, conhecimentos que extrapolavam o conteúdo manifesto. 


\section{A GASTRONOMIA NO MUNDO E NO TURISMO}

A alimentação é uma das necessidades básicas de todo indivíduo. Entretanto, a gastronomia é expressão de uma coletividade, expressão de uma cultura. Muito além da simples função nutricional e satisfação de uma necessidade biológica individual; cozinhar é uma prática socialmente construída, representando uma expressão dos mais variados desejos, ideias, necessidades e conflitos de todos os povos e em todas as épocas.

A clássica disputa, teórica e metodológica, entre Harris (1994) e seu expressão de "bom para comer" e Lévi-Strauss (2004) "bom para pensar" sintetizam as duas dimensões da arte de cozinhar e saborear. De uma parte, para Lévi-Strauss (2004), um alimento é bom porque satisfaz as necessidades simbólicas do pensamento coletivo. Ou seja, comer ou não comer porco, vaca, coelho, cavalo ou cachorro, por exemplo, depende da estrutura de significados atribuída a esses animais em cada cultura. De outra parte, para Harris (1994), a comida deve satisfazer as necessidades materiais do sistema econômico, antes de alimentar a consciência coletiva. Nesse sentido, no sistema capitalista contemporâneo, "en grado cada vez mayor, lo que es bueno para comer es lo que es bueno para vender” (HARRIS, 1994, p. 273).

Falk (1990) destaca a relevância da alimentação, desde os primórdios da espécie humana. $\mathrm{O}$ autor correlaciona a postura bipedal ou postura alimentar, a própria evolução do cérebro humano e todas as evoluções que sucedem ao ser humano. Em outras palavras, Falk (1990) afirma que a evolução do ser humano ocorreu pela busca dos alimentos. Neste sentido, diversos outros importantes acontecimentos da história estão relacionados à alimentação, como foi o caso das Grandes Navegações no século XV, em que as especiarias, tais como a pimenta, o gengibre, a canela e outros temperos, fizeram os europeus cruzarem fronteiras e mares, na busca de novas rotas para obter esses alimentos.

O alimento também se faz presente na história do Brasil. No Brasil colônia, a cana-de-açúcar era o símbolo do desenvolvimento nas capitanias, que deram origem aos estados nordestinos. Nos séculos XVI e XVII, a cana-de-açúcar trouxe fortunas, não só econômicas, mas também arquitetônicas e artísticas. Por outro lado, a própria cana-de-açúcar também trouxe a escravidão e a desigualdade social, herdada de uma estrutura social oligárquica. $\mathrm{O}$ alimento, portanto, assim como o seu cultivo e os hábitos alimentares, cumpre um papel fundamental na história e delineiam economias, culturas e identidades de um povo (FREYRE, 2007).

Com base nessas análises, constata-se que, dentro do processo civilizador (ELIAS, 2011), a alimentação supera a sua primitiva finalidade: alimentar o ser humano, e passa a desempenhar uma importante função sociocultural e econômica. Posteriormente, os alimentos alcançam o status de gastronomia, ao passar a serem concebidos sob um complexo paradigma de natureza hedonista.

Para Dória (2009, p.13), a gastronomia é o "procedimento comparativo que indica as melhores formas de tratamento de um determinado produto, dentro de uma determinada sociedade ou grupo, com uma configuração de gosto particular”. Ainda segundo o autor, a culinária é "o conjunto de transformações materiais por que passam as matérias-primas alimentares até serem consumidas, incluindo tecnologias, tabus alimentares, etc" (DÓRIA, 2009, p.13). Em outras palavras, culinária é a metamorfose do alimento, é a transformação dos ingredientes por meio de técnicas específicas de preparo; enquanto gastronomia é a especialização da técnica, agregada de valores sensoriais, que se somam ao valor simbólico, para satisfazer prazeres de uma necessidade física ou sociocultural. A alimentação e o alimento adquirem, neste sentido, uma nova dinâmica nas sociedades contemporâneas, caracterizada pela gastronomia.

Para Dietz (2009), a comida tradicional como gastronomia é tangível, materializada em um prato, mas também intangível, pois associa valor simbólico e representações simbólicas ao ato de alimentar-se. Ainda segundo este autor, a comida tradicional tem a finalidade de satisfação física (fonte de energia), mas também psíquica (satisfação, desejo).

Montanari (2008, p.153) afirma que “as identidades além de mutáveis no tempo, são múltiplas” e cada uma encontrará a mais apropriada, diversificada e diferente forma de se expressar na alimentação. Para Montanari 
(2008), essa diversidade de expressões no ato de se alimentar não deve ser entendida como antagônicas, mas sim complementares, múltiplas, tal como as identidades.

Montanari (2008) ressalta ainda a nítida influência das cozinhas migratórias nos territórios, ao considerar que assim como a língua falada,

o sistema alimentar contém e transporta a cultura de quem a pratica, é depositário das tradições e da identidade de um grupo. Os imigrantes carregam consigo a gastronomia que reflete suas preferências, suas identificações, atribuindo a essa um valor simbólico especial, por vezes saudosista, que reforça o sentimento de pertencimento ao lugar de origem. Constitui, portanto, um extraordinário veículo de auto representação e de troca cultural (MONTANARI, 2008, p. 183).

A gastronomia apresenta-se, portanto, como signo de identidade, mas também como um excelente modo de experimentar novas culturas. No intercâmbio cultural, o turismo pode representar um forte aliado para a disseminação e valorização das gastronomias dos lugares. Contudo, é necessária uma análise mais detalhada desta afirmação, pois a suposta identidade gastronômica de um lugar turístico, por vezes, é o resultado de ações conjuntas de governos e empresários, para mercantilizar a cultura e fazer dela um "espetáculo para dar resposta às expectativas do turista” (CAMPBELL, 1995). Isto porque o turismo muito influencia a mercantilização da gastronomia do lugar, na busca de engrandecer e evidenciar um destino.

No âmbito da Gastronomia Típica, há uma concreta possiblidade de criar um exímio atrativo turístico, associando história e cultura, carregando ingredientes, modo de preparo e apresentação, com valores simbólicos que reforçam e legitimam a identidade do lugar. A Gastronomia Típica torna-se, portanto, um segmento de grande valor para o turismo.

\section{A GASTRONOMIA COMO PRODUTO TURÍSTICO}

Nas sociedades contemporâneas, ao se consumir qualquer produto ou serviço não está presente apenas o valor econômico, mas também o sociocultural. O diferente, o singular é cada vez mais valorizado economicamente e socioculturalmente, contribuindo para o esforço da preservação do legado cultural dos territórios. Neste sentido, para reafirmar a identidade territorial, os territórios têm investido no que se identifica com a história, a geografia e as tradições do seu povo. É no singular dos territórios, que a atividade turística assume cada vez mais protagonismo. Para Harvey (2005, p. 233), “o que está em jogo é o poder do capital simbólico coletivo, isto é, o poder dos marcos especiais de distinção vinculados ao lugar, dotados de um poder de atração importante em relação aos fluxos de capital de modo geral".

Existe na atualidade uma grande busca de destinos turísticos exóticos. Como ressaltam Castro e Santos (2012, p.161), existe a "mercantilização da etnia e da alteridade, da venda do espaço e da cultura do 'outro' para o 'eu', sendo a diferenciação dos destinos determinante para a sua atratividade e valor de mercado". Por outro lado, a espetacularização do patrimônio territorial, o ato de transformar saberes, hábitos e tradições em bens de consumo pode ser negativo, quando se resume às finalidades puramente econômicas e menospreza a relevante ferramenta de intercâmbio cultural contida nessas relações.

De outra perspectiva, quando a participação ativa dos autóctones no planejamento da oferta turística identifica uma relação de respeito aos valores culturais, sendo a mercantilização dos bens materiais e imateriais uma consequência dos arranjos territoriais, a atividade turística pode ser um indutor de desenvolvimento, com ênfase nos valores culturais (BRASILEIRO, 2012,2015). Nesta ótica, a gastronomia pode ser um canal de valorização cultural, que agrega valores econômicos para os autóctones.

A gastronomia pode promover, portanto, a aproximação entre a cultura do lugar e a cultura do visitante. Os espaços de alimentação, como os restaurantes, são espaços com finalidade nutritiva e, cada vez mais, cumprem também uma função cultural, ao difundir, por meio da alimentação, os modos de ser e de viver de um povo. Esta aproximação se concretiza por meio da alimentação e também dos intercâmbios entre os turistas e os autóctones. A função dos espaços de alimentação é, portanto, mais do que alimentar-se: tornam-se espaços 
de aproximação e de legitimação de culturas, criando pontes de aprendizagens e experiências culturais entre os visitantes e visitados.

Assim mesmo, quando se associa a gastronomia a um determinado território, por muitas vezes tem-se também uma forte ferramenta de marketing territorial. Alimentar-se é uma necessidade comum a todos os humanos. Por isso, o marketing tem, na alimentação, um produto pronto, de fácil promoção e com forte apelo comercial. Um produto como a gastronomia, possui uma extensa variedade de oferta, tais como comida étnica, saudável, vegana, além do valor simbólico associado a tal oferta. Como produto, a gastronomia é capaz de adaptar-se ao paladar dos mais diversos públicos e gostos, podendo assim ser consumido por muitos.

Este fato vincula a cultura gastronômica do território à principal motivação dos turistas para muitas viagens aos mais diversos destinos (RICHARDS, 2002). Imagens dos territórios ilustram sabores, exalam aromas, despertam o desejo dos turistas curiosos, que desejam experimentar comidas exóticas comparativamente aos seus padrões alimentares. Por essa razão, muitos turistas cruzam fronteiras em busca de conhecer in loco as tradições gastronômicas dos territórios.

Dentro do turismo, portanto, a Gastronomia Típica se apresenta como um atrativo turístico territorial, tanto no âmbito gastronômico, como no cultural, seja como atrativo principal ou como coadjuvante. Para Quan e Wang (2004), as motivações dos turistas para o consumo alimentar estão associadas à curiosidade sobre a gastronomia local e/ou a necessidade de alimentar-se, uma vez que o turista se encontra fora da sua residência e precisa satisfazer suas necessidades básicas.

Henriques e Custódio (2010) ressaltam que, no que se refere ao consumo alimentar na atividade turística, há sempre expectativas da parte do turista, traduzida algumas vezes em apreensão ao conhecer um prato típico de um território. Isto porque a Gastronomia Típica dos territórios remete aos turistas, uma nova experiência e um novo sabor, marcados pela "autenticidade" da gastronomia do lugar, podendo atrair os neofílicos, receptivos a novidades, assim como afastar os neofóbicos, adversos a novidades (QUAN; WANG, 2004).

Outra questão que circunda a Gastronomia Típica como atrativo turístico é a autenticidade (FOX, 2007). A autenticidade deste tipo de gastronomia é muitas vezes um mito ou ainda uma releitura, uma representação da realidade que se deseja demonstrar e rememorar. Portanto, essa autenticidade gastronômica é definida pelos autores como a própria superficialidade do ato turístico. Henriques e Henriques (2010) salientam que a maneira de se alimentar na contemporaneidade é um retrato de invenções desses últimos 200 anos. Isto quer dizer que, assim como os territórios e as culturas, a gastronomia também é dinâmica, e a autenticidade de determinadas Gastronomias Típicas é um processo de construção e reconstrução que se concretizaram ao longo do tempo.

No caso da atividade turística, este processo muitas vezes acontece de forma mais rápida. Cria-se uma representação da Gastronomia Típica que pode ser mercantilizada sob a insígnia do autêntico, do típico, ainda que esta autenticidade não corresponda à realidade dos alimentos autóctones. Vende-se a ilusão da Gastronomia Típica quando, na realidade, se está preenchendo a satisfação do turista, ao corresponder às suas expectativas de consumo. Frequentemente, as identidades das gastronomias de um país são reduzidas a um prato, como se aquele prato representasse a multiplicidade cultural que compóe a história gastronômica do país.

Lévi-Strauss (1978, p.129), neste sentido, ressalta que a busca pela autenticidade tem um "sentimento de nostalgia, de um tempo perdido e irreversível”, que não será mais alcançado e que se confunde no anseio paradoxal de retomar algo que já passou, mas que não se pretende, verdadeiramente, voltar por completo ao tempo dado da memória vinculada. Como exemplo, os sabores da infância que se desejam retomar, mas sem voltar a ser criança, ir à escola, submeter-se às regras dos adultos, entre outras condições que pertencem à condição do ser criança (HENRIQUES; HENRIQUES, 2010).

Certos pratos têm o poder, portanto, de transportar a memória para momentos e espaços de aconchego e celebração: a tapioca nos leva ao nordeste, tanajuras fritas aos contos de Monteiro Lobato lidos durante a 
infância, mugunzá remete às festividades juninas. São guloseimas marcadas de personalidade e história. No exterior, a comida permite aos imigrantes recordarem sua pátria, ajuda a superar a saudade e a reafirmar, por meio da gastronomia, sua identidade, seu país. Assim também acontece com o turista, que busca restaurantes étnicos para se aproximarem da lembrança de uma viagem memorável.

A Gastronomia Típica, concebida como atrativo turístico é, na contemporaneidade, uma resposta às expectativas desse novo perfil de turista, que anseia por ícones culturais; representa, também, uma releitura do autóctone pelo próprio turista, pela sua auto-representação, a ser degustada (MONTANARI, 2008).

O tradicional da Gastronomia Típica, associado ao dinamismo cultural da contemporaneidade, pode representar novas perspectivas de desenvolvimento ao território. Considerando o autóctone como o real detentor do saber da Gastronomia Típica e do seu simbolismo, o envolvimento desses autóctones na elaboração e comercialização das iguarias gastronômicas, pode promover o desenvolvimento territorial e legitimar a autenticidade da gastronomia do lugar.

A Gastronomia Típica, portanto, é promotora de identidades e geradora de desenvolvimento territorial.

\section{A GASTRONOMIA PESSOENSE NO GUIA BRASIL QUATRO RODAS}

\subsection{Sobre o Guia Brasil Quatro Rodas}

Comemorando 50 anos de existência em 2015, o Guia Brasil Quatro Rodas é uma publicação anual, da Editora Abril S.A. Este é o guia impresso mais utilizado pelos brasileiros que buscam informações turísticas nacionais. Segundo a própria editora, em pesquisa realizada em 2012, "é o maior e o mais importante guia de turismo do Brasil" (GUIA BRASIL, 2012, p.3).

Nas primeiras páginas, o leitor recebe orientações para decodificar os signos que aparecem no guia, utilizando-se, da melhor maneira, das informações publicadas. Ainda nas páginas iniciais do verbete "Use bem seu guia”, explicam-se os ícones gráficos empregados em cada edição e também a metodologia para escolher e avaliar os restaurantes, hotéis e atrações. O guia ressalta, ainda, os testes utilizados nos restaurantes, que são sempre realizados no anonimato. Convites e cortesias não são aceitos. Este fato contribui para a confiabilidade dos testes realizados.

Todos os restaurantes selecionados pelo guia são visitados e submetidos a uma ficha padrão de avaliação, em que os jornalistas atribuem notas para couvert, entrada, prato e sobremesa. O quesito "prato" contém, ainda, sete outros sub-quesitos, com pontuações diferentes: apresentação; temperatura; qualidade dos ingredientes; cozimento; harmonia; tempero e sensação final. Após a avaliação, o jornalista avaliador se identifica e realiza uma visita à cozinha do restaurante, para verificar condições de higiene, armazenamento e procedência dos ingredientes (GUIA BRASIL, 2015).

As características da avaliação realizada pelo Guia Brasil Quatro Rodas nos restaurantes, no período analisado para este estudo, mantiveram o mesmo padrão da ficha e sistema de atribuição das notas, que é construída com base em uma escala que vai de fraco, regular, bom, muito bom a excelente. Em 2015, no entanto, não há explicações da graduação da nota, considerando-se que foi a mesma dos anos anteriores. Desde 2005, para destacar os melhores avaliados, estrelas são atribuídas na descrição dos restaurantes pelo guia. Segunda a própria explicação do texto (GUIA BRASIL, 2015, p.12), as estrelas "indicam restaurantes de cozinha acima da média, que oferecem uma experiência gastronômica memorável, independentemente da faixa de preço e do nível de conforto". A qualidade dos ingredientes e o desempenho da equipe da cozinha são aspectos determinantes para a concessão deste prêmio.

O restaurante avaliado, além de aparecer com destaque na publicação ao ser contemplado com as estrelas, recebe também uma "placa honrosa" para ser exibida no estabelecimento, reconhecendo o valor que o próprio restaurante e consumidores atribuem ao prêmio. Para a editora e seus jornalistas, a competição pelas estrelas 
do guia entre os restaurantes demonstra a credibilidade e relevância do trabalho realizado pela equipe. Tal competição gera mais visibilidade e prestígio ao guia relativamente aos restaurantes premiados.

A edição de 2011 é uma das mais inovadoras dos últimos dez anos. Isto porque esta edição foi o marco em que o guia adotou um ícone gráfico, para indicar a "escolha do guia". Este ícone contempla os escolhidos, no começo da descrição do estabelecimento que, independentemente da categoria de conforto, se destacaram positivamente na relação custo-benefício, ambiente ou atendimento.

A diversidade gastronômica também começa a ganhar mais notoriedade a partir de 2011. Não somente os restaurantes aparecem nas indicações gastronômicas, mas também confeitarias, pastelarias, cafés, bares, entre outros estabelecimentos que servem "bons lanches rápidos e econômicos - bufês por quilo e as chamadas comidinhas" (GUIA BRASIL, 2011).É, portanto, a partir do ano de 2011 que o guia começa a atribuir valor aos pequenos momentos de "comidinhas" - merendas, cafés, lanches rápidos. Certamente, os momentos de "comidinhas" também fazem parte da experiência gastronômica dos leitores-turistas, representando assim mais um interessante momento para se conhecer os sabores do lugar que se visita, intensificando a experiência turística.

A edição de 2015 também é inovadora pois o guia, pela primeira vez, decide indicar os restaurantes em ordem alfabética, divididos por especialidades. Até o ano de 2014, com base nos critérios de avaliação realizada pelos jornalistas da equipe, as indicações limitavam-se a avaliar a qualidade da cozinha (GUIA BRASIL, 2015, p.12). A classificação pela qualidade da cozinha podia ser considerada uma fragilidade do guia, pois, a partir de critérios de um avaliador, restaurantes com propostas diferentes eram comparados e hierarquizados. Ao organizar por ordem alfabética, o guia deixa de impor sua visão aos restaurantes, para assumir e reconhecer a autonomia do leitor, em escolher e julgar o que lhe parece melhor, haja vista que a sucinta quantidade de indicações já representa, por si só, um filtro para o olhar do turista que não busca outras fontes de informação.

\subsection{A Gastronomia pessoense no Guia Brasil}

A gastronomia pessoense, da cidade de João Pessoa, capital da Paraíba, divulgada pelo guia, é dividida nas oito categorias, com uma média de dois restaurantes indicados por categoria: comida típica; carnes (rodízio); culinária francesa, italiana, regional, pescados, portuguesa e variada, além de comidinhas e bares. A quantidade de indicações - dois restaurantes por categoria - manteve-se praticamente a mesma ao longo do período analisado, ou seja, de 2005 a 2015. Neste período de dez anos não foram acrescentadas outras categorias, e os restaurantes indicados foram praticamente os mesmos. Houve uma pequena variação, devido ao fechamento de alguns estabelecimentos, sendo assim substituídos por outros.

A maioria dos restaurantes divulgados está presente em todas as publicações analisadas, com destaque para um restaurante pessoense de comida regional, que possui filial em outros estados brasileiros. Não há, portanto, variações nas indicações gastronômicas da cidade divulgadas pelo guia.

A falta de novas indicações da gastronomia da cidade nas oito categorias do guia, no período analisado, pode passar a falsa impressão de que não houve inovação nem crescimento do setor no cenário gastronômico de João Pessoa. Isto quer dizer que a ideia associada às informações contidas no guia, com os mesmos lugares com "os mesmos sabores", pode influenciar negativamente a experiência turística dos visitantes que buscam por novos sabores, sensações e inovações gastronômicas.

O guia apresenta uma sólida trajetória dos restaurantes indicados e a certeza da qualidade. Este fato pode contribuir para que o guia não se arrisque em indicar novos lugares gastronômicos, que, porventura possam não corresponder às expectativas dos turistas. Outra interpretação deste fato pode estar associada a um perfil mais conservador do guia, já que ele apresenta um padrão rígido e muito técnico para avaliar os restaurantes, o que se reflete na homogeneização e contínua indicação dos mesmos estabelecimentos em dez anos. 
O padrão de avaliação utilizado pelo guia valoriza a técnica e a cozinha, subestimando o espaço social do restaurante, visto que não há, na ficha, nenhum aspecto de avaliação social, como perfil dos clientes que frequentam o restaurante: faixa etária; gênero; estado civil; entre outros aspectos como música ambiente; luz intimista; descontração. As indicações são de cunho mais tradicional e conduzem os visitantes a terem uma experiência gastronômica previsível, ainda que o cenário gastronômico na cidade seja diversificado e ativo, cabendo, ao setor de alimentos e bebidas, a taxa de crescimento mais expressivo no ramo de serviços (GUIA ABRASEL PB, 2014).

Outra proposta de avaliação, valorizando aspectos sociais, o valor agregado ao produto e ao serviço, assim como a experiência oferecida por meio da comida, conduziria os leitores-turistas a novas experiênciasmemórias, consequentemente, uma experiência turística mais rica, válida e memorável, contribuindo para a consolidação do destino.

$\mathrm{Na}$ categoria "comida típica", uma breve resenha se encarrega de apresentar a gastronomia característica da Paraíba. Durante sete anos, de 2007 a 2014, dos dez anos analisados, o discurso associado à comida é o mesmo, ou seja, associando a gastronomia da cidade ao sertanejo:

O sertanejo é, antes de tudo, um apreciador de comida forte. Como no sertão se acorda cedo e trabalha-se muito, a culinária é vigorosa e calórica, principalmente nas refeições feitas pela manhã e ao cair da noite. O cardápio é extenso: carne de sol, feijãoverde, galinha caipira, arroz de leite, feijão-de-corda com carne de bode, rubacão (feijão, arroz, charque, queijo e legumes), baião de dois (arroz, feijão e queijo coalho), paçoca (carne de sol assada e desfiada, socada no pilão com farinha), fava, buchada de bode e sarapatel (refogado de miúdos de porco ou de bode). Para a sobremesa, uma caprichada alquimia de doces, como a pamonha, a tapioca, o queijo coalho assado com mel de engenho (caldo de cana cozido) e a coalhada com rapadura e alfenim (massa clara feita com mel de engenho). (GUIA BRASIL, 2007, p.518).

Apenas duas vezes, nos anos 2005 e 2006, o Guia fez referência à constituição da cozinha típica, como resultado de uma hibridização, ou seja, mistura de duas ou mais culturas que formam uma nova (CANCLINI, 1995). Esta hibridização se apresenta com as influências da cultura portuguesa e indígena (GUIA BRASIL, 2005). Este fato é destacável, ao reconhecer as diversas influências na construção da identidade gastronômica nordestino-paraibana. Por outro lado, destaca-se também como a gastronomia apresentada como típica de João Pessoa, cidade do litoral paraibano, foi desde 2007 até a edição de 2015 do Guia, diretamente associada à gastronomia típica do sertão e à figura alegórica do sertanejo.

No conteúdo do Guia, os hábitos alimentares são, assim, estigmatizados pela reprodução da caricata figura do sertanejo, em que este trabalha sob o sol, no árduo plantio, imagem que também foi construída e enfatizada por meio das mídias, ao relatar o drama da seca, do acordar cedo e precisar de uma alimentação nutritiva para encarar o longo e duro dia que lhe aguarda. Neste sentido, ressaltando Bourdieu (2012), a lógica do estigma só pode ser compreendida numa luta pela imposição de uma determinada classificação e definição da identidade:

As lutas a respeito da identidade étnica e regional, quer dizer, a respeito de propriedades (estigmas ou emblemas) ligadas à origem através do lugar de origem e dos sinais duradouros que lhe são correlativos, como o sotaque, são um caso particular das lutas das classificações, lutas pelo monopólio de fazer ver e fazer crer, dar a conhecer e de fazer reconhecer, de impor a definição legítima das divisões do mundo social e, por este meio, de fazer e desfazer os grupos. (BOURDIEU, 2012, p. 113).

Um conteúdo retrógado que tenta uma falida "reprodução" e adaptação da emblemática fala de Euclides da Cunha (1982, p, 170) “O sertanejo é, antes de tudo, um forte”, no livro Os sertôes, publicada originariamente em 1902. Paradoxalmente, ao destino de praia e mar, que tanto se vende nas publicações turísticas, a mídia ainda insiste em propagar uma imagem reducionista, ao retratar o nordeste como um grande sertão e, o nordestino, como um sertanejo e/ou retirante da seca.

As perspectivas de representação, ao menos no âmbito gastronômico, parecem mais positivas a partir de 2015, onde a resenha de comida típica, por exemplo, não possui mais o conteúdo, por vezes, pejorativo, da identidade nordestina/sertaneja. Nesta edição de 2015, o Guia se limita a citar os nomes dos pratos. Entretanto, esta mudança não é suficiente, pois não contribui para a afirmação da identidade nordestinoparaibana nem para a consolidação de um destino gastronômico. 
A ênfase e a homogeneização do nordestino-paraibano como o homem sertanejo, por meio da gastronomia, retratam a dificuldade do "outro", o turista, reconhecer os traços peculiares e determinantes da composição das múltiplas identidades da Paraíba, na sua diversidade regional, tais como o Brejo, o Cariri, o Litoral, o Curimataú, o Sertão etc.

O nordeste é uma complexa região formada por um amplo mosaico cultural em que peculiaridades marcam e definem cada território. A diversidade gastronômica da Paraíba, mais especificamente a de João Pessoa, é uma parte desse mosaico cultural.

\section{CONSIDERAÇÕES FINAIS}

A ideia reproduzida por meio do discurso gastronômico no Guia Brasil Quatro Rodas sugere que a capital paraibana tem a comida sertaneja como sua identidade gastronômica. Embora a culinária típica normalmente não retrate a comida cotidiana, a justificativa propagada pelo Guia na escolha da cozinha sertaneja como "típica" de João Pessoa é reducionista na medida em que cria a imagem e a cultura do sertão em uma cidade do litoral.

Apesar de a capital dispor de uma significativa oferta gastronômica, a cozinha sertaneja é descaracterizada em João Pessoa posto que foi adaptada com ingredientes próprios da zona costeira, como é o caso do "Rubacão com camarão". A ausência de uma diversificada, popular e também sofisticada gastronomia nordestinoparaibana resulta da depreciação do patrimônio gastronômico paraibano, posto que é apresentada de forma reducionista e alegórica, tal como se apresenta no Guia.

O Guia Brasil Quatro Rodas revela, em uma linguagem mais familiar ao seu público-alvo - turistas do sul e sudeste do Brasil -, os ingredientes da cozinha pessoense quase como uma tradução simultânea da composição da gastronomia do sertão. Diferentemente do discurso fabuloso e marcado por adjetivações turísticas, a resenha gastronômica apresentada no Guia não conta com um apelo comercial ou turístico muito forte, pois, em vez de atrair os visitantes, parece distanciá-los, ao afirmar que a comida da região é pesada e própria para aqueles que "acordam cedo e trabalham muito".

O discurso apresentado pelo Guia Brasil Quatro Rodas sobre a gastronomia de João Pessoa não enaltece os produtos da terra e, tampouco, a descreve como uma experiência gustativa agradável, pois a caracteriza como uma cozinha "vigorosa e calórica". Assim mesmo, os pratos regionais, quando "traduzidos", não apresentam nenhum atrativo sensorial que desperte o desejo dos leitores em conhecer nossa gastronomia e região.

É possível que exista uma limitação de caracteres na edição do Guia, mas as descrições dos pratos poderiam ser mais convidativas se nelas fossem inseridas informações do contexto histórico e sociocultural, o que contribuiria, inclusive, para instigar o interesse do leitor a viver uma experiência turística em terras paraibanas.

\section{REFERENNCIAS}

BARDIN, L. Analise de conteúdo. Lisboa: Edições 70, 2009.

BARROCO, L. M. S. A importância da Gastronomia como Patrimônio Cultural, no Turismo Baiano. TURyDES: Revista de investigación en turismo y desarrollo local. Málaga (España), v. 1, n. 2, março. 2008. Disponível em:http://www.eumed.net/rev/turydes/02/sbb.htm . Acesso: 20 de julho de 2017.

BOURDIEU, P. La distinción. Critérios y bases sociales del gusto. Madrid: Taurus, 1988.

BOURDIEU, P. O poder simbólico. Rio de Janeiro: Bertand Brasil, 2012.

BOTELHO, R. B. A. Culinária Regional: o Nordeste e a Alimentação Saudável. Tese em Ciências da Saúde. Brasília: Brasil, 2006.

BRASIL, Ministério do Turismo. Programa de Regionalização do Turismo. Roteiros do Brasil: Módulo Operacional 1, Sensibilização. Brasília: Ministério do Turismo, 2004. 
BRASILEIRO, M. D. S. Pluralidade metodológica: um diálogo entre o qualitativo e o quantitativo nas ciências sociais. In: DINIZ, A.; BRASILEIRO. M. D.; LATIESA, M. (Org.). Cartografias das novas investigações em sociologia. João Pessoa: EDUFPB, 2005.

. Desenvolvimento e turismo: para além do paradigma econômico, In: Brasileiro, M. D. S.; Medina, J. C. C.; Coriolano, L. N.: Turismo, cultura e desenvolvimento. Campina Grande: EDUEPB, 2012.

O trabalho imaterial na construção do desenvolvimento e das novas territorialidades. In: Brasileiro, M. D. S.; Medina, J. C. C.; Desenvolvimento Territorial, Cultura e Turismo: uma abordagem multidisciplinar. Campina Grande: EDUEPB, 2015.

CANCLINI, N. G. Culturas híbridas: estrategias para entrar y salir de la modernidad. Buenos Aires: Sudamericana, 1995.

CAMPBELL, C. The Romantic Ethic and the Spirit of Modern Consumerism. Oxford: Blackwell, 1995.

CASTRO, F. M. M., SANTOS J. G. M. A cultura gastronômica como atrativo turístico: relato de uma experiência de pesquisa nos Restaurantes de Aracaju/SE. Revista Hospitalidade. São Paulo, v. IX, n. 2, p. 155 - 174, jul.- dez. 2012. Disponível em; http://www.eumed.net/rev/turydes/02/sbb.htm. Acesso em 20 de julho de 2017.

CUNHA, Euclides da. Os sertões. São Paulo: Círculo do Livro, 1982.

CUNHA, K. B.; OLIVEIRA, L. V. A. Gastronomia enquanto atrativo turístico-cultural. Artigo para Conclusão de Curso de Pós-Graduação, Goiás: Universidade Estadual de Goiás, 2009.

DA MATTA, R. O que faz do Brasil, Brasil? Rio de Janeiro: Rocco, 1991.

DENZIN, N. K.; LINCOLN, Y. S. (Editores). The SAGE Handbook of Qualitative Research. Califórnia: Thousand Oaks, 2000.

DIETZ, A. Take away entre fronteiras: comida e sentimento de pertencimento entre migrantes italianos na Irlanda do Norte. Revista Espaço Plural. Marechal Cândido Rondon, v. 10, n. 20, p. 11-20, jan - jun, 2009. Disponível em: http://e-revista.unioeste.br/index.php/espacoplural/article/view/2448/1848. Acesso em 20 de julho de 2017.

DÓRIA, C. A. A formação da culinária brasileira. São Paulo: Publifolha, 2009.

ELIAS, N. O processo civilizador: uma história dos costumes. Rio de Janeiro: Zahar, 2011.

FAGLIARI, G. S. Turismo e alimentação: análises introdutórias. São Paulo: Roca, 2005.

FALK, D. Brain evolution in Homo: The "radiator" theory. Behavioral and brain sciences. 13:333-344, 1990. Disponível em: http://www.academia.edu/3214946/Brain_evolution_in_Homo_The_radiator_theory. Acesso em 20 de março de 2014.

FREYRE, G. Açúcar. Uma Sociologia do doce. São Paulo: Global, 2007.

FOX, R. Reinventing the gastronomic identity of Croatian tourist destinations", International Journal of Hospitality Management, 26 (2007) 546-559. Disponível em: http://www.sciencedirect.com/science/article/ pii/S0278431906000247 Acesso em 20/02/2015.

Guia ABRASEL PB 2014/ 2015. Paraíba, 2014

Guia Brasil Quatro Rodas 2005. São Paulo: Ed. Abril, 2004.

Guia Brasil Quatro Rodas 2007. São Paulo: Ed. Abril, 2006.

Guia Brasil Quatro Rodas 2011. São Paulo: Ed. Abril, 2010.

Guia Brasil Quatro Rodas 2012. São Paulo: Ed. Abril, 2011.

Guia Brasil Quatro Rodas 2013. São Paulo: Ed. Abril, 2012.

Guia Brasil Quatro Rodas 2014. São Paulo: Ed. Abril, 2013.

Guia Brasil Quatro Rodas 2015. São Paulo: Ed. Abril, 2014.

HARRIS, M. Bueno para comer. Madrid: Alianza, 1994.

HARVEY, D. A produção capitalista do espaço. São Paulo: Annablume, 2005.

HENRIQUES, C.; CUSTODIO, M. J. Turismo e Gastronomia: a valorização do património gastronómico na região do Algarve. Encontros Científicos, Faro, n. 6, 2010. Disponível em: http://www.scielo.oces.mctes.pt/ scielo.php?pid=S1646-24082010000100008\&script=sci_arttext. Acesso em 20 de fevereiro de 2015. 
HENRIQUES, C.; HENRIQUES L. Turismo, Cultura e Gastronomia. O caso do produto Gastronomia \& Vinhos no Algarve (Portugal). Anais do VI SEMINTUR, Mestrado em Turismo, Universidade Caxias do Sul. 2010.

LÉVI-STRAUSS, C. The origin of Table Manners. London: Harper \& Rowe, 1978.

LÉVI-STRAUSS, C. O cru e o cozido. Mitológicas 1. São Paulo: CosacNaify, 2004.

MONTANARI, M. Comida como cultura. São Paulo: Editora Senac, 2008.

QUAN, S.; WANG, N. Towards a structural model of the tourist experience: an illustration from food experiences in tourism, Tourism Management 25 (2004), p. 297-305. 2004 Disponível em: http://www.sciencedirect.com/ science/article/pii/S0261517703001304>.. Acesso em 20 de fevereiro de 2015.

RICHARDS, G. Gastronomy: an essential ingredient in tourism production and consumption. Tourism and Gastronomy. Routledge, p.3-20. 2002. Disponível em: http://www.sciencedirect.com/science/article/pii/ S0261517703001304>. . Acesso em 20 de março de 2015.

SILVA, E. L.; MENEZES, E. M. Metodologia da pesquisa e elaboração de dissertação. Florianópolis: Laboratório de Ensino a Distância da UFSC, 2001.

SILVA, Paula Pinto e. Farinha, feijão e carne seca: um tripé culinário no Brasil colonial. São Paulo: Senac, 2005.

CC BY 